\author{
Lisandra Espíndula Moreira \\ Universidade Federal do Rio Grande do Sul
}

Henrique Caetano Nardi

Universidade Federal do Rio Grande do Sul

\title{
Mãe é tudo igual? Enunciados produzindo maternidade(s) contemporânea(s)
}

\begin{abstract}
Resumo: Este artigo analisa os enunciados relativos à maternidade que configuram o que chamamos de "norma" da maternidade. Seguimos as reflexões de Foucault, principalmente no que se refere à genealogia como forma de pensar o presente. Utilizamos o relato das trajetórias de mulheres que são mães e trabalhadoras para a produção dos materiais de análise. Os materiais possibilitaram a problematização de alguns enunciados que constituem a maternidade na contemporaneidade. Descrevemos a intensificação do investimento em um padrão de mulher mãe que tem como produto uma norma da maternidade. Essa norma da maternidade, apesar de ser produzida socialmente, passa a ser naturalizada. Ela funciona associando algumas características a um modo de ser mãe considerado mais adequado, tais como tempo e idade certos para ser mãe, número de filhos, condições financeiras. A partir dela, outros modos de ser mãe são avaliados e hierarquizados.
\end{abstract}

Palavras-chave: maternidade; enunciado; discurso; modos de subjetivação.

Copyright (c) 2009 by Revista Estudos Feministas.

${ }^{1}$ Ditado popular.

2 Esta reflexão é parte de uma pesquisa mais extensa sobre maternidade e trabalho com mulheres inseridas em diferentes contextos sociais, a dissertação de mestrado de Lisandra Espíndula Moreira, sob orientação de Henrique Caetano Nardi. Durante a realização desse estudo, a mestranda contou com o apoio de uma bolsa fornecida pela CAPES.

\section{Introdução}

"Mãe é tudo igual, só muda de endereço."1 O que torna possível pensar que mulheres inseridas em diferentes contextos sociais ao se tornarem mães passam a ser iguais? Este artigo tem como objetivo principal compreender os enunciados relativos à maternidade ${ }^{2}$ que configuram o que chamamos de norma da maternidade, norma esta que possibilita a ideia de um padrão para a maternidade, configurando um modo de ser mãe como mais adequado e legítimo. Para buscar dar conta desse objetivo, partimos da perspectiva genealógica, baseada nas teorizações de Michel Foucault, analisando o relato das trajetórias de vida de mulheres que são mães e trabalhadoras. 
${ }^{3}$ Robert CASTEL, 1998, p. 23.

${ }^{4}$ Michel FOUCAULT, 1995.
${ }^{5}$ FOUCAULT, 2005.
A genealogia está sendo utilizada aqui como uma forma de pensar o presente, uma vez que, como afirma Robert Castel, "o presente não é só o contemporâneo. É também um efeito de herança, e a memória de tal herança nos é necessária para compreender e agir hoje". ${ }^{3}$ Nesse sentido, a genealogia entende a história partindo da ideia de proveniência - herança, conjunto de falhas, fissuras, inscrição dos acontecimentos no corpo - e de ponto de emergência-o surgimento como fruto de uma luta de forças. ${ }^{4}$

Os materiais produzidos para análise derivam dos relatos de trajetórias de vida de mulheres que são mães e trabalhadoras. Ao todo, participaram da pesquisa 14 mulheres, contatadas através de redes institucionais ou pessoais, residentes em Porto Alegre, Rio Grande do Sul. Buscamos entrevistar mulheres com distintas origens e inserções sociais, levando em conta marcadores como nível de escolaridade, faixa de renda, tipo de inserção no mercado de trabalho, faixa etária e cor da pele. Ao longo do texto descrevemos esses marcadores sociais, quando destacamos trechos dos relatos que dão conta da especificidade de cada trajetória.

$\mathrm{Na}$ entrevista, inicialmente, as participantes forneciam algumas informações objetivas sobre seu contexto social e, em seguida, solicitávamos que falassem da sua história de vida. Nesse sentido, a duração do relato variava bastante e, em alguns casos, acontecia em mais de uma entrevista. Além dessa pergunta inicial, seguimos um roteiro de questões elaboradas a partir da revisão bibliográfica, buscando destacar os aspectos relativos à relação trabaIho-maternidade-contexto social. No relato das trajetórias de vida foi possível analisar a relação das mulheres consigo mesmas e com o contexto social no qual se inserem. Além disso, foi possível compreender e descrever como a maternidade atravessa os processos de subjetivação dessas mães, explicitando os enunciados que constituem a maternidade hoje. O entendimento dos processos de subjetivação dessas mulheres não acontece mergulhado somente nas suas histórias individuais, como se ali estivesse a razão ou o sentido último para as suas falas, mas na articulação dessa trajetória com o contexto sócio-histórico mais amplo.

Partindo das trajetórias de vida das mulheres, buscamos construir uma análise genealogicamente orientada, compreendendo as tensões que se fazem presentes nas relações entre os modos de maternar em diferentes contextos sociais. Essas tensões se evidenciam nos enunciados que atravessam os relatos dessas mães trabalhadoras. Descrever e compreender um enunciado, como propõe Foucault, ${ }^{5}$ é entender a relação do relato com um campo enunciativo adjacente e com a posição possível ocupada pelo sujeito que fala, situando-o em um determinado tempo e contexto social. 
6 Diferenciamos no texto as citações que foram produzidas no campo (trechos das entrevistas) colocando-as em itálico. Tal estratégia foi escolhida para que a citação seja entendida através da condição em que foi produzida, diferenciando-se de textos acadêmicos, que obedecem a um formato e a uma linguagem específicos. Não se quer, com essa distinção, estabelecer diferenças hierárquicas entre o saber presente na fala das participantes e o saber escrito em artigos ou livros, mas assumir que são produzidos diferentemente.

${ }^{7}$ Tomamos algumas medidas para preservar a identidade das participantes, por isso os nomes são fictícios, as idades podem variar dentro de um intervalo de três anos, o trabalho é citado através da área de atuação, conforme aprovação do Comitê de Ética em Pesquisa, do Instituto de Psicologia, da Universidade Federal do Rio Grande do Sul. Sempre que citamos a fala de uma participante, colocamos em nota algumas informações.

Janete tem 57 anos, é branca, separada, tem quatro filhos $e$ trabalha na área da educação. $A$ renda familiar depende praticamente dela e se situa entre 5 e 10 salários mínimos.

${ }^{8}$ FOUCAULT, 1988, p. 100.

\section{Mãe é tudo igual? Configurações da(s) ma-ternidade(s) contemporânea(s)}

De uma forma geral, analisando os diferentes enunciados que conformam a maternidade, percebemos que os sentidos a ela associados não são assim tão diferentes. Encontramos muitas preocupações semelhantes, dilemas idênticos e mesmas dificuldades na forma de lidar com os filhos. Há características que são relatadas como específicas de um modo de ser mãe, as quais configuram a norma relativa à maternidade, a partir da qual as mães 'se' avaliam como 'boas' mães, ou não, utilizando-se, para isso, de diferentes discursos.

Através dessas semelhanças, torna-se possível destacar o enunciado que nomeia este trabalho e que parte de um ditado popular: "Mãe é tudo igual, só muda de endereço." Tal enunciado atravessa a fala de Janete, quando reflete sobre as dificuldades e os aprendizados da maternidade: "Porque não muda muito sabe, só muda os endereços, os problemas são os mesmos. E me olhando, me observando. Se isso era uma coisa repetitiva e que eu tinha pisado na bola, o que eu fiz, revendo as minhas posições, meus comportamentos" (Janete). $^{7}$

Podemos nos perguntar aqui: como se configura esse modo de ser mãe para mulheres inseridas em contextos tão diferentes? Quais discursos estão implicados na construção de uma determinada forma de maternidade considerada a mais adequada?

Buscando uma compreensão ampliada sobre a norma que define a maternidade atualmente, hierarquizando as diferentes possibilidades de ser mãe, é possível apontála como um dos aspectos do "dispositivo da sexualidade", tal como definido por Michel Foucault:

\begin{abstract}
A sexualidade é o nome que se pode dar a um dispositivo histórico: não à realidade subterrânea que se apreende com dificuldade, mas à grande rede da superfície em que a estimulação dos corpos, a intensificação dos prazeres, a incitação ao discurso, a formação dos conhecimentos, o reforço dos controles e das resistências, encadeiam-se uns aos outros, segundo algumas estratégias de saber e de poder. ${ }^{8}$
\end{abstract}

Tal conceito é trabalhado pelo autor ao identificar, a partir do século XVIII, quatro grandes conjuntos estratégicos que desenvolvem enunciados específicos, caracterizando relações de saber e poder a respeito do sexo. São eles: 1) histerização do corpo da mulher, em que o corpo feminino passa a se comunicar organicamente com o corpo social, com o espaço familiar e com a vida das crianças; 2) pedagogização do sexo da criança, que é entendida como 
9 FOUCAULT, 1988, p. 131.

${ }^{10}$ Marilyn YALOM, 1997.

"Elizabeth BADINTER, 1998.

ser sexual "liminar"; 3) socialização das condutas de procriação, associando a questões econômicas, políticas e médicas; e 4) psiquiatrização do prazer perverso, análise, normalização de condutas e técnicas corretivas no caso de anomalias sexuais.

Neste estudo podemos pensar que existem estratégias que atuam diretamente sobre o corpo das mulheres ao tornarem-se mães - a histerização do corpo da mulher e a socialização das condutas de procriação. No entanto, esse dispositivo funciona de formas diversas e também se configura a partir de outras estratégias que vão conformando o corpo dessa mulher através do biopoder, "técnicas buscando a sujeição dos corpos e o controle das populações". 9 A biologia torna-se alvo da poltica. O poder centrado na vida tem como efeito uma sociedade normalizadora que constrói parâmetros de conduta e julgamento que investem o corpo. Analisando esses investimentos na mulher que a posicionam de forma distinta no que chamamos de gesto da vida - o biopoder -, outras autoras propõem reflexões sobre as condições que tornaram possível esse movimento. Marilyn Yalom ${ }^{10}$ atenta para a "politização do seio feminino", relacionada com a urbanização, o fortalecimento do sistema capitalista de produção e a consolidação dos estados nacionais. Elizabeth Badinter ${ }^{11}$ chama atenção para a transformação nas práticas de cuidado dispensadas à criança. Associa a "invenção" do amor materno ao discurso econômico (importância da população e controle da mortalidade) e filosófico (expressão do amor através das ideias do lluminismo), situando as mulheres como intermediárias e interlocutoras entre o Estado e a família e localizando-as como responsáveis pelo futuro das nações.

A norma descrita na fala dessas mulheres mantém muitos traços herdados desses movimentos anteriores, que tornaram possível a construção da maternidade. Além disso, há hoje o fortalecimento de alguns enunciados que compõem essa norma e que intensificam seus efeitos. ${ }^{12}$ Dagmar Meyer nomeia esse processo como "politização da maternidade", que "não é inovadora, mas que atualiza, exacerba, complexifica e multiplica investimentos educativo-assistenciais que têm como foco mulheres mães". ${ }^{13}$

Tal intensificação nos discursos é percebida de diferentes formas pelas mulheres. Nas entrevistas, no entanto, essa percepção ficou mais evidente no relato das mulheres mais velhas, visto que algumas têm a possibilidade de acompanhar agora a criação dos netos e percebem essa diferença:

É muito complicado, hoje em dia está mais difcil de criar do que na época que eu criei meus três filhos. A mentalidade mudou completamente tudo está mais perigoso, mais caro. É mãe na fila do hospital 
14 Lisete tem 53 anos, é branca, casada desde os 16 anos, tem três filhos e trabalha na área de limpeza. Sua renda familiar não chega a dois salários mínimos.

\footnotetext{
${ }^{15}$ MEYER, 2006.

${ }^{16}$ Henrique Caetano NARDI (2006) relaciona o neoliberalismo com três medidas adotadas pelos países como forma de tornar a economia competitiva, após a crise do fordismo, nos anos 1970: a ruptura da estrutura sindical como forma coletiva e solidária de reivindicação, a submissão das políticas sociais à lógica do mercado e a restauração da taxa de desemprego. Como efeito, tem-se a acentuação do individualismo e a mercantilização das relações, ultrapassando os limites econômicos e produzindo modos de ser nesse contexto.

17 MEYER, 2006, p. 88.
}

\footnotetext{
${ }^{18}$ Mara tem 50 anos, é negra, separada, voltou a estudar e faz faculdade. Tem dois filhos, de 26 e 20 anos. Trabalha com políticas públicas ligadas à questão da criança e do adolescente, não tendo uma renda garantida todos os meses. A renda familiar se situa entre 2 e 5 salários mínimos, contando com o rendimento do exmarido, com quem mora.
}

pra ganhar, fazer exames, acompanhamento médico. Hoje em dia talvez eu não planejasse mais os três. (Lisete) ${ }^{14}$

A politização da maternidade se produz através de redes de poder-saber que configuram práticas de intervenção (políticas e programas, instrumentos diagnósticos, linhas educativas). Essas redes estão atravessadas por diferentes discursos (médico, moral, psicológico, religioso, pedagógico, jurídico) e diferentes processos sociais, econômicos e políticos, sendo, nesse processo, identificadas pela autora quatro forças sociais ao longo do século XX: a racionalidade neoliberal, a globalização, o desenvolvimento tecnocientífico e a multiplicação de sujeitos de direito. ${ }^{15}$

A racionalidade neoliberal ${ }^{16}$ relaciona-se com a maternidade através da ideia de que cada indivíduo é responsável pelas suas escolhas e de que essas devem estar direcionadas sempre para seu aperfeiçoamento, que, nessa racionalidade, está acessível a todos. As políticas e os programas que constituem esse movimento afirmam que:

gerar e criar filhos equilibrados e saudáveis passa a ser social e culturalmente definido, também, como um projeto de vida, responsabilidade individual de cada mulher que se torna mãe, independentemente das condições sociais em que essa mulher vive e dos problemas que ela enfrenta. ${ }^{17}$

A responsabilização da mãe e da família ('desestruturada') como causa e também efeito de transformações e problemas sociais fica explicitada na seguinte fala: "Eu estou vendo muito problema familiar, desajustamento da família, violência, falta de carinho, compreensão, eu penso, que cada dia é mais difícil ser mãe e pai" (Mara)..$^{18}$

Essa fala, em sintonia com o enunciado relacionado racionalidade neoliberal, é possível para Mara pela posição que ocupa na atuação em políticas direcionadas à proteção de crianças e adolescentes. Recebe crianças e jovens em situações de maus-tratos, abuso, negligência. Nesse trabalho, a estratégia de atuação se centra na educação dos pais, responsabilizando-os pelos cuidados ou, no limite, afastando-os de seus filhos.

Tal racionalidade se propaga através da globalização, que se reflete de modo distinto na vida das mulheres, em especial das mais pobres. Um dos efeitos desses movimentos caracteriza-se pela 'feminização da pobreza', que, no Brasil, um país fortemente racializado, está marcada não somente pelo gênero, mas também pela cor. Um desdobramento dessa questão pode ser vislumbrado nas políticas e nos programas direcionados às populações que vivem abaixo da linha da pobreza, produzindo diferenças e efeitos 
19 MEYER, 2006, p. 90.

${ }^{20}$ MEYER, 2006, p. 90.

de poder em suas classificações, como populações de risco, populações vulneráveis, sem explicitar "a complexidade das dinâmicas de classe, raça/etnia, gênero ou inserção regional que estão imbricadas na (e articuladas ) produção dessas situações". ${ }^{19}$

Os efeitos dessa conjunção apresentam-se também na fala de Mara.

Hoje tem um grupo muito grande de mulheres sozinhas, e por várias razões, não querem saber do marido, do pai da criança, entáo acaba ficando pra ela essa tarefa de cuidar, a não ser que more perto da mãe, do pai, que daí as avós cuidam, mas se é uma mulher sozinha, às vezes, ela não consegue cumprir esse papel e por $n$ razões: histórico de vida, necessidade [...]. (Mara)

Apesar de fazer referência à falta de um suporte social, mesmo assim, as mães são valoradas conforme se aproximam ou não desse ideal de cuidado associado à maternidade. O que fica explicitado é o quanto se espera que a mães seja uma pessoa cuidadora, mesmo que ela também esteja imersa nas mesmas relações de violência:

Porque quem tem que proteger não protege. Porque o que é a figura da mãe? É a que protege, tá aculturado. O pai não está. Aí por um motivo ou outro, por paixão, por necessidade, acaba não protegendo. $E$ têm outras que são umas guerreiras. Teve um caso lá, ele abusou da filha dela, ela largou tudo, a casa boa e foi morar com os pais pra proteger a filha. (Mara)

Outro conjunto de enunciados que configuram a maternidade se associa ao desenvolvimento técnicocientífico. As relações de poder e saber tomam novas formas através de tecnologias do corpo, as quais" descrevem e monitoram, antecipada e minuciosamente, o desenvolvimento físico, cognitivo e emocional do feto, inscrevendo-se numa rede de controle e regulação da vida". ${ }^{20}$ Apesar de estarem muito presentes na questão do desenvolvimento fetal (pelas biotecnologias genéticas e tecnologias de imagens - ultrassonografia), entendemos que esses controles e regulações ultrapassam essa etapa e permanecem monitorando e descrevendo os corpos durante todo o desenvolvimento humano.

Aline, profissional da saúde, particularmente atravessada por esse discurso, fala sobre as dificuldades nos primeiros meses da filha:

Eu achei que eu ia ser bem mais light, mais fácil. $A$ Manoela já na eco fetal já mostrou uma dilatação no sistema urinário, podia ter refluxo urinário, saiu 
${ }^{21}$ Aline tem 29 anos, é branca, trabalha na área de saúde, direcionada para o atendimento à criança, é casada e tem uma filha. Sua renda familiar está entre 10 e 20 salários mínimos.

22 FIDALGO, 2003.
${ }^{23}$ Raquel tem 29 anos, é negra, tem um filho de 11 anos, é solteira e trabalha na área político-partidária. Sua renda familiar é de 2 a 5 salários mínimos. do hospital tomando medicação pra refluxo urinário, filha de profissional da saúde, aí fez ecografia, fez outro exame e graças a deus não tinha, mas nesse meio tempo ela começou com refluxo gastroesofágico, era um estresse no início porque ela tinha dor. Chorou muito no início, eu me perdi bastante, achei que ia ser bem mais fácil. (Aline) ${ }^{21}$

Para Lurdes Fidalgo,22 apesar da quantidade de informações e tecnologias disponíveis às mães, as quais fornecem a essas atividades domésticas um ar de profissionalismo, retira-se dessas mulheres a confiança e colocaas na dependência de peritos. Essa é a característica desse movimento que a autora denomina "maternidade científica", impulsionada predominantemente pelo discurso médico, transformando a maternidade num campo quase técnico.

O último movimento dessa politização contemporânea da maternidade diz respeito à multiplicação de sujeitos de direito. Nesse sentido, os enunciados que definem os direitos humanos são entendidos tanto como conjunto de formula-ções fundamentais da sociedade quanto como relações de poder específicas de contextos históricos, sendo uma constante tensão entre políticas de Estado e movimentos sociais, que colocam em questão a noção de direito univer-sal. $O$ direito passa a ser desdobrado: direitos sexuais e repro-dutivos, direitos da mulher, direitos da criança e do adoles-cente, em certos países, até direitos do feto. Nesse sentido, estabelece uma luta de forças na busca por legitimidade, quando esses direitos se contrapõem.

Ao refletir sobre as mudanças que percebe na maternidade, Raquel, uma de nossas entrevistadas, faz uma relação interessante entre as transformações no modo de ser mãe e as transformações na política da infância, com a implantação do Estatuto da Criança e do Adolescente (ECA), as quais demandam uma nova forma de cuidar, a seu ver, diminuindo o poder dos pais perante os filhos:

[o que mudou?] A mídia, a criação, a educação. $A$ criação do ECA - Estatuto da Criança e do Adolescente. Já aconteceu de eu ter vizinhos que estavam brigando com as crianças e as crianças chamarem a polícia para os pais, isso também atrapalha porque o filho é meu e eu que tenho que criar, claro que tem os limites não vou dizer que eu tenho que matar a pau, mas isso influencia. (Raquel) ${ }^{23}$

Algumas transformações sociais (violência, direitos da criança, regras de cuidado infantil e incentivo a atividades para mulheres mais velhas) são relatadas como elementos que dificultam o exercício da maternidade, também na associação com o trabalho (transformado, exigindo constante qualificação): 
${ }^{24}$ MEYER, 2006, p. 84.

\footnotetext{
${ }^{25}$ No geral, esta frase está associada à canção de Heckel Tavares (1896-1969), intitulada Casa de cabloco. Os versos dizem "numa das casas de cabloco, um é pouco, dois é bom, três é demais", associando à ideia de um relacionamento amoroso que deveria ser monogâmico. Mas o sentido da frase, não sua forma, pode ter raiz bem mais antiga. No entanto, 0 uso desse dito, em relação ao número de filhos, é recente, como fica explícito na análise que segue.
}

É que antes elas [a mãe e a avó] podiam sair para rua só para trabalhar. Hoje a gente tem que sair para rua para trabalhar, estudar, fazer curso, fazer especialização, fazer seminário, fazer isso, fazer aquilo. Antes era fácil, tu podia sair e deixar teu filho com qualquer pessoa, hoje não dá. Antes as mães aceitavam ficar com os filhos da gente. Hoje não, elas querem ir para o bingo, para o baile da terceira idade, elas não querem mais (Raquel).

Essas transformações intensificam os enunciados que configuram a politização da maternidade: "É na conexãoprovisória e historicamente situada-de diferentes discursos sobre a maternidade ou de alguns de seus elementos que se materializa a produção de outro discurso, aparentemente unitário, sobre 'a' maternidade e é nesse processo que se define o que chamamos de politização". ${ }^{24}$

É na atualização da norma, a partir da qual as mulheres mães são chamadas a exercer essa função, que se produz a ideia de uma igualdade feminina, a qual se faz presente no ditado que dá nome ao presente artigo. Pensamos que a igualdade aqui relatada, além de ser um efeito discursivo, refere-se mais ao conjunto de exigências que são colocadas para as mulheres como mães do que a uma uniformidade no modo efetivo com que elas exercem a maternidade.

O reconhecimento da maternidade através dessa norma segue a rede enunciativa que determina, por exemplo, o número de filhos adequado, o tempo e a idade certos de ser mãe, as condições (econômicas) para a maternidade. Enunciados que, associados a diversos discursos, emprestam legitimidade a certos modos de ser mãe, passando a ter maior valor social.

\section{Análise das trajetórias: a configuração da norma}

\section{Um é pouco, dois é bom e três é demais}

Uma das características que configuram a normalização da maternidade refere-se à regulação do número de filhos. Aqui se encaixa o ditado que diz: "Um é pouco, dois é bom e três é demais". ${ }^{25} \mathrm{O}$ número de filhos ideal, definido socialmente, é dois, mas não por qualquer razão, tal ideia vem recheada de diferentes significados.

Por que um é pouco? A figura de filho único é vista como problemática e está associada a um discurso psicológico sobre o desenvolvimento infantil, o qual vincula um bom desenvolvimento também à possibilidade de desenvolver uma relação fraternal.

Nessa linha, ocorre a vontade de ter o segundo filho, não como um desejo de ser mãe pela segunda vez, mas 
${ }^{26}$ Débora tem 31 anos, é branca, tem uma filha de 1 ano e meio, trabalha na área jurídica e é casada. A renda da família está na faixa de 5 a 10 salários.
${ }^{27}$ Márcia tem 38 anos, é branca, casada, tem dois filhos (com 9 e 11 anos). Tem curso superior $e$ especialização e trabalha na área comercial. A renda familiar é superior a 20 salários mínimos. associada unicamente ao desejo de dar um irmão para o primeiro filho: "Eu penso em outro filho pra dar um irmãozinho pra Bibiana, eu penso nela. Eu acho chato ela crescer sozinha, ela não ter um irmão [...] eu não queria privar a Bibiana disso. Eu te diria: 'eu não tenho a necessidade de ter outro filho', eu não tenho isso" (Débora). ${ }^{26}$

O número dois é estabelecido como um ideal. Livrase o primeiro filho do "rótulo" de filho único e, de certa forma, se garantem alguns investimentos (afetivos e financeiros) que hoje são entendidos como necessários para as crianças. 0 número excessivo de filhos passa a ser compreendido como uma das causas de privações para as crianças, ou seja, as famílias que têm mais filhos não conseguiriam dar condições adequadas para todos, da mesma forma que famílias que têm apenas dois: "Eu pelo menos penso assim. Menos filhos, tu tens condições de dar mais as coisas. Mais filhos, é mais complicado. Pra eles não passar o que a gente passou [...] Deus me livre, meus filhos passarem o que eu passei" (Mara).

Na contextualização desse relato é importante ressaltar os efeitos da urbanização. Numa situação rural, de agricultura familiar, a prole extensa era também uma estratégia de existência, já no contexto urbano, as condições de existência da família tornam-se responsabilidade exclusiva dos pais (o trabalho passa a ter um espaço separado do espaço doméstico, destinado apenas aos adultos). Nesse contexto, quanto menor a prole, melhores serão as condições de vida oferecidas aos filhos.

A responsabilidade dos pais passa a ser maior com a urbanização. O filho, que antes era visto como alguém que ajudava na manutenção da casa, agora passa a ser mais uma despesa. Mara se orgulha do fato de os filhos não precisarem sair muito jovens para trabalhar, podendo ter um tempo maior de preparação e qualificação, fazendo cursos e estágios. Semelhante preocupação foi apontada por Márcia, lembrando-se das estratégias da mãe na sua infância para dar condições de vida para os seis filhos: " $A$ mãe sempre foi muito econômica [...] para poder dar um estudo para os filhos, criar os filhos [...] se não, não tinha condições. Foi bem difícil, imagina, com seis filhos, nessas condições a gente já nasce competindo" (Márcia). ${ }^{27}$

Ela relata que antes queria também ter seis filhos, como seus pais, mas hoje não quer mais que seus dois filhos. O limite no número de filhos está associado à possibilidade de dar melhores condições financeiras para a prole e também à sua posição como trabalhadora. No caso de ter outro filho, precisaria repensar o seu trabalho. Os investimentos de tempo e dinheiro, que entende serem necessários para a criança, hoje não cabem na sua agenda. 
28 Bila SORJ, Adriana FONTES e Danielle Carusi MACHADO, 2007.
As condições e necessidades que são colocadas como necessárias para a criação de uma criança foram sofrendo mudanças, foram sendo ampliadas. Analisando, a partir de uma perspectiva genealógica, o enunciado que estabelece o número ideal de filhos, podemos delinear uma descontinuidade histórica. Essa descontinuidade se dá na reconfiguração da normalização da maternidade e não quer dizer que não existam práticas associadas ao ideal anterior, mas significa que elas são tensionadas também por essas mudanças. Os significados antes associados a uma família que tinha um número grande de filhos se transformam juntamente com o que se entende como uma família com muitos filhos.

Se antes famílias com muitos filhos eram famílias com mais de 10, hoje uma família com mais de dois já é considerada grande. Além disso, ter muitos filhos era sinônimo de uma família saudável, jovem, produtiva. Hoje, uma família muito grande é tida como irresponsável (não se planejou, não se cuidou), ou seja, uma família desleixada e fortemente associada à pobreza. Essa ruptura fica explícita nesta fala:

Naquela época quem tinha pouco filho era feio, sinal de que tinha algum problema de saúde [...] Minha amiga de infância, cheguei lá (na cidade natal) há uns oito anos atrás, ela estava no $11^{\circ}$ filho e eu disse "quando tu vai parar?", "ah, tem que ver que eu ainda sou nova". Nossa que ridículo, porque eu sou nova. (Mara)

Tal possibilidade de mudança de sentidos em relação ao número de filhos parece ser possível pelo desenvolvimento científico das técnicas de contracepção e também pelo maior investimento exigido para o cuidado dos filhos, da nuclearização progressiva da família, da urbanização, das conquistas do feminismo, do ingresso da mulher no mercado de trabalho e do encarecimento do custo de vida. A maternidade deixa de ser uma consequência "natural" de uma vida heterossexual ativa e passa a ser uma escolha da mulher ou do casal.

Essa escolha pode ter como efeito a possibilidade de uma melhor inserção da mulher no mercado de trabalho. Numa análise sobre essa inserção, Bila Sorj, Adriana Fontes e Danielle Machado ${ }^{28}$ atentam para o fato de a diminuição do número de filhos significar uma importante redução do "trabalho reprodutivo", aumentando a capacidade de as mulheres se inserirem no mercado e de as famílias conciliarem trabalho e responsabilidades familiares. Ao mesmo tempo que isso abre certa margem de escolha, possibilitando um planejamento, também cria a figura de uma maternidade irresponsável, quando o número de filhos se 
${ }^{29}$ lara tem 40 anos, é casada, mãe de três filhos $(15,11$ e 9 anos), tem superior completo e especialização, trabalha como empresária na área de educação. A renda familiar é superior a 20 salários mínimos. torna maior do que o esperado socialmente. Isso porque parece impensável que as pessoas possam planejar e desejar ter mais de dois filhos.

Um atravessamento importante na definição de um número ideal de filhos é o discurso presente na definição das políticas de natalidade, pois estabelecer se a política será de controle ou pró-natalidade implica um campo de tensões. Além disso, dentro de um mesmo país, há diferenças nos índices de natalidade conforme as populações, por exemplo, no que tange à renda e ao nível de escolaridade. Podemos retomar, aqui, a dimensão do biopoder, que tem, numa das suas estratégias de controle da vida e da população, a regulação da natalidade, seja para estimulá-la, seja para diminuí-la. Está presente, nessa forma de ação política sobre a vida, uma posição privilegiada de sujeito a partir da qual as mulheres são capturadas e definidas como cidadãs.

E por que três filhos é demais? No relato das trajetórias de vida, a experiência de ter mais de dois filhos foi associada à vergonha, inadequação, chegando a ser descrita em dois relatos como associada ao diagnóstico de depressão. Na trajetória de Janete, durante sua quarta gravidez foi o momento em que ela subverteu algumas regras no que se espera de uma 'boa mãe' (gravidez não foi planejada, situação financeira instável, longe da família e recebendo ajuda financeira):

Eu comecei a trabalhar e dois meses depois eu engravidei, então eu entrei em depressão. Passei os dois primeiros meses da gravidez em alta depressão, que eles saíam de casa e quando eles voltavam eu estava sentada no mesmo lugar que eles me deixaram e ainda de pijama [...] Então foi bem difícil esse filho. E nós lá sem dinheiro. Minha mãe me mandando dinheiro. Eu morria de vergonha de dizer para minha mãe que eu estava grávida de novo pela quarta vez. Então eu até entendo minha depressão. (Janete).

lara também relata que sofreu muito quando ficou grávida do seu terceiro filho, porque achava que era um absurdo ter mais um filho, mesmo que em sua família fossem comuns proles muito maiores. Sua mãe teve dez irmãos (um falecido pequeno) e seu pai, 11 (três falecidos pequenos):

A última pessoa que eu contei foi para minha mãe, porque eu tinha vergonha que eu estava grávida do terceiro filho. Porque ter três filhos para mim, representa ter muitos filhos. $E$ assim, se eu pensar a minha vó sempre reclamou por ter tido dez filhos. Então tem coisas que eu acho que eu aprendi com minha vó. (lara) ${ }^{29}$ 
${ }^{30}$ Kátia Rosa AZEVEDO e Alessandra da Rocha ARRAIS, 2006.
Além disso, parece estar implicada nessa questão da quantidade de filhos uma dúvida sobre quem pode ter mais de dois filhos ou em que situações ela teria direito a mais um filho: "É que na época, eu senti uma situação muito de dependência da minha mãe. Então naquele momento eu não podia ter outro filho. Como é que eu ir ter mais um filho, se ela já me ajudava" (lara).

Um atravessamento importante nessas falas é o do discurso médico e psicanalítico, primeiro pelo fato de que as duas mulheres tiveram experiência de terapia (uma faz atualmente e a outra já fez), o que lhes dá um vocabulário bastante sintonizado com esse discurso. Além disso, associam a sua experiência a um diagnóstico, o que lhes confere um lugar possível de sujeito, lugar este que tem se tornado bastante comum.

Kátia Azevedo e Alessandra Arrais ${ }^{30}$ problematizam a questão da depressão pós-parto a partir do que chamam de "mito da mãe exclusiva", isto é, como uma condição que torna possível e produz tal sofrimento. A análise das autoras aponta $o$ quanto pode ser prejudicial para as mulheres uma representação de maternidade na qual a mãe é infalível em tempo integral. As autoras centram-se nas práticas de cuidado consideradas adequadas e que exigem das mães dedicação exclusiva, no entanto, podemos ampliar essa reflexão não apenas para as questões relativas ao cuidado infantil e que definem o que é uma boa mãe, mas também para as questões que configuram esse ideal materno, inclusive quanto à restrição ao número de filhos.

Além disso, ampliando essa problematização, entendemos que a definição de uma categoria diagnóstica específica para esse período - depressão pós-parto subentende que o momento da chegada de um filho deve ser vivido com alegria, festejo, independente do que configura a situação atual dessa mãe, dessa família. Não temos a intenção de aprofundar o tema da depressão pósparto, mas também não temos como ignorar que a normalização da maternidade, seja pelas exigências de condições afetivas, financeiras, sociais, seja pelo estabelecimento do número de filhos, de uma idade para ser mãe, tenha, sim, um custo subjetivo bastante alto para algumas mulheres. Não estamos, nesse sentido, questionando aqui o diagnóstico com a sintomatologia e os riscos que o acompanham. Entretanto, a partir dessa reflexão, podemos pensar que esse diagnóstico é situado historicamente, ou seja, as condições que o tornaram possível de ser nomeado e inteligível estão dadas nesse contexto, pela forma como hoje se toma a maternidade. 
31 Utilizo aqui estes termos "gravidez na adolescência, "maternidade tardia e "maternidade precoce" porque é dessa forma que eles circulam e são produzidos nos enunciados. No entanto, podemos problematizá-los, pois as definições do que seria tardio ou precoce são produzidas e precisam ser entendidas como efeitos desse momento histórico.

${ }^{32}$ Laurence TAIN, 2005.

\section{O tempo certo de ser mãe}

Esse enunciado que define um tempo 'certo' para ser mãe pode ser considerado um dos aspectos que marcam a normatividade sobre a maternidade. Além de propor como ideal uma maternidade por volta dos 30 anos, traz em si outras definições em relação ao tempo e à idade da maternidade. Esse enunciado categoriza as maternidades que fogem desse ideal, como, por exemplo, a gravidez na adolescência $^{31}$ - tão estudada e associada aos grandes problemas sociais contemporâneos - e a maternidade tardia para mulheres que têm filhos depois dos 40 . Para além da idade da mãe, o tempo da maternidade pode ser relacionado também com a idade dos filhos. Nesse sentido, a idade dos filhos, sua dependência ou autonomia, produz modos específicos de ser mãe.

Há algumas falas que apresentam a maternidade tardia como um fenômeno atual associado à livre escolha da maternidade, ou seja, à possibilidade de recusá-la ou postergá-la em função das técnicas contraceptivas, e à maior inserção feminina no mercado de trabalho, assim como à maior exigência de qualificação das/dos trabalhadoras/es. Tal concepção é analisada no contexto francês por Laurence Tain, ${ }^{32}$ relacionando a escolha do momento para a maternidade, à luz das tecnologias reprodutivas. A autora alerta para a necessidade de entender a maternidade tardia a partir das relações de gênero - construção social que se utiliza de algumas diferenças biológicas para constituir também modos de ser mãe e pai (diferenças no limite de idade para a entrada em programas de fertilização, inicialmente para mulheres é de 40 anos e para homens é de 55 anos) - e do contexto social e político, conexão entre o nível cultural das mulheres e o calendário dos nascimentos $^{33}$ (quanto maior o nível de escolaridade, maior seria a idade da mulher ao tornar-se mãe).

Tal diferença definiria também uma inserção mais desigual no mercado de trabalho:

A chegada precoce de uma criança e as restrições específicas que a acompanham, no caso das muIheres, em um contexto em que o trabalho doméstico não é compartilhado de maneira equivalente entre os dois sexos, não pode deixar de limitar o futuro profissional das mulheres. ${ }^{34}$

Para além dessa constatação, podemos pensar as condições que tornaram possível associar, por exemplo, o nascimento de uma criança a restrições para a mãe e a uma limitação de seu futuro profissional. No contexto brasileiro, os dados dos Indicadores e Dados Básicos da Saúde - IDB ${ }^{35}$ mostram que existe uma relação clara entre a

${ }^{35}$ REDE INTERAGENCIAL DE INFORMAÇÕES PARA A SAÚDE, 2008. 
${ }^{36}$ Michele tem 35 anos, é branca, casada, mora com o companheiro e tem dois filhos (com 8 e 2 anos). Tem superior completo na área de exatas e, no momento, gerencia um setor numa empresa privada. A renda familiar está acima de 20 salários, sendo $90 \%$ provenientes do seu trabalho.

escolaridade e a idade da mãe no que se refere aos nascidos vivos em 2007, assim como em relação à situação geográfica, ou seja, quanto maior a escolaridade, maior a idade da gestante. Também no que diz respeito à região do país, as gestantes do Sul e do Sudeste (regiões mais ricas) são mais velhas que as gestantes do Norte, Nordeste e Centro-Oeste (regiões mais pobres). A 'maternidade tardia' pode ser tomada como um modo de articulação entre trabalho e maternidade, produto das transformações nessas duas esferas. Numa tentativa de darem conta das exigências tanto do trabalho, através de uma dedicação intensa e qualificação constante, quanto da maternidade, protelando o nascimento do primeiro filho para um momento em que também possam dedicar-se intensamente ao bebê, algumas mulheres decidem ser mães depois de certa idade.

Eu sempre quis ter um filho, lembro que quando eu era pequena eu dizia pra mãe, "mãe, se eu não casar eu vou ter um bebê" [...] mas com o passar do tempo, com a profissão eu meio que me esqueci desta história de ser mãe, em 97 eu acordei um dia e disse que queria ter um bebê. (Michele) ${ }^{36}$

O efeito desse modo de ser mãe é a produção de um descompasso, um contraste entre o tempo de conquista das condições que são entendidas como necessárias para o nascimento de um filho (consolidação profissional, condições financeiras, estabilidade conjugal) e o tempo biológico (período de fertilidade feminina e disposição associada à juventude).

Para Raquel, esse contraste se torna ainda mais marcado quando pensa em ter o segundo filho e condiciona isso à conquista de melhores condições de vida. Além disso, suas possibilidades de trabalho e renda não permitem que essas condições sejam alcançadas em curto prazo:

Eu gostaria, mas não sei se vai dar tempo. Eu já tenho vinte e nove anos [...] Até eu alcançar todos esses objetivos que a gente falou. Parece que é fácil, mas demanda tempo. Talvez daqui a dez anos daí eu vou estar com quarenta. Com quarenta anos eu não vou ter filho [...] É, eu não vou ter mais filhos não porque eu não quero, porque não vai dar tempo de eu me estruturar. (Raquel)

A maternidade programada para depois de certa idade está diretamente associada às condições que se imaginam como ideais para a chegada de um/a filho/a, e não apenas ao desejo de tê-lo/a, que pode estar presente desde muito antes na vida de uma mulher. De certa forma, mantém uma tentativa de corresponder aos enunciados que definem o que é uma boa mãe e o que é ser uma boa traba- 
${ }^{37}$ RIO GRANDE DO SUL, 2006.

${ }^{38}$ Mariza ABREU apud RIO GRANDE DO SUL, 2007.

${ }^{39}$ Eliane Reis BRANDÃO e Maria Luiza HEILBORN, 2006.
Ihadora, além de explicitar as desigualdades sociais que diferenciam mulheres inseridas em contextos sociais distintos.

No outro extremo, há uma grande preocupação em relação à gravidez na adolescência. Essa é tomada como uma gravidez diferente, associada a riscos específicos, físicos e sociais e que demandam atenção e cuidados.

No Rio Grande do Sul, até final de 2006, existia a campanha Te Liga. Gravidez Tem Hora, destinada a jovens dos 10 aos 19 anos e suas famílias. Segundo as argumentações do programa, "a maternidade precoce, que alcança índices de $20 \%$ a cada 100 partos de nascidos vivos no Rio Grande do Sul, e 1 milhão, na maioria de famílias pobres, em todo o Brasil, deve ser tratada como um problema social pelas conseqüências negativas para os jovens e suas famílias". Citam-se como exemplos dessas consequências "o abandono da escola, o desemprego, a desestruturação da família, as dificuldades em educar os filhos, além de complicações na saúde da gestante". ${ }^{37}$

Com a mudança de governo, a questão é trabalhada através do planejamento familiar, mantendo a mesma associação da gravidez na adolescência com problemas sociais: "Se tratarmos a gravidez precoce na escola, teremos menos problemas de saúde, menos problemas de segurança e menos evasão escolar". ${ }^{38}$ O absurdo dessa fala é que ela estabelece uma relação de causa e efeito direta entre a gravidez na adolescência e os problemas existentes nas áreas de educação, saúde e segurança.

Lisete entende isso como um grande problema atual associado à falta de planejamento e irresponsabilidade, mesmo que ela tenha sido mãe aos 16 anos:

Hoje em dia a vida tá muito cara, ainda bem que tive só três. No terceiro, fiz ligadura. Eu vejo lá na minha comunidade, meninas com 16 anos, 17 anos com quatro, cinco filhos, elas não se programam, não se cuidam, não usam camisinha, é uma coisa que não é planejada. (Lisete)

O argumento de que esse é um 'problema' social, segundo Eliane Brandão e Maria Luiza Heilborn, ${ }^{39}$ baseiase, na sua maioria, em investigações com camadas populares e circula com tons alarmistas e moralizantes, associando esse evento à desinformação juvenil, às dificuldades de acesso aos métodos contraceptivos, à pobreza e às situações de marginalidade social. A gravidez na adolescência teria como consequências a constituição de uma prole numerosa, o incremento das famílias monoparentais, a esterilização precoce, o abandono escolar e a precária inserção no mercado de trabalho. 
${ }^{40}$ Estela Maria Motta Lima Leão de AQUINO et al., 2003; BRANDÃO e HEILBORN, 2006; HEILBORN et al., 2002; e Ana Lídia Nauar PANTOJA, 2003.

${ }^{41}$ BRANDÃO e HEILBORN, 2006, p. 1422.

42 Janine Raymundi ESTEVES e Paulo Rogério Meira MENANDRO, 2005.

${ }^{43}$ BRANDÃO e HEILBORN, 2006.

${ }^{44}$ PANTOJA, 2003.
Pensando as condições sociais e históricas de emergência dessa questão, podemos desnaturalizar a gravidez na adolescência como um problema social: ${ }^{40}$

Parir antes dos 19 anos, décadas atrás, não se constituía em assunto de ordem pública. As alterações no padrão de fecundidade da população feminina brasileira, as redefinições na posição social da mulher, gerando novas expectativas para as jovens, no tocante à escolarização e profissionalização e o fato da maioria destes nascimentos ocorrer fora de uma relação conjugal despertam atenção para o fato. ${ }^{41}$

Dentre as transformações no cenário familiar, as autoras atentam para as mudanças na infância, o redimensionamento da autoridade parental, as novas normas educativas, as transformações nas relações de gênero e entre gerações. Associam-se, também, as transformações em outras esferas que se traduzem numa maior dependência dos jovens em relação aos pais, como a extensão da escolarização e as dificuldades de inserção e permanência no mercado de trabalho.

Nesse sentido, a gravidez na adolescência só pôde ser produzida como um problema social diante das expectativas depositadas nos jovens atualmente, principalmente nas adolescentes do sexo feminino (escolarização, inserção profissional e exercício da sexualidade desvinculado da reprodução). Nesse momento, então, a gravidez é entendida como um desperdício de oportunidades, uma subordinação - precoce - à função materna. Dessa forma, supõe-se como universal o valor ou o projeto de novas funções femininas.

Na constituição desse modo de ser mãe (na juventude) como um problema, encontramos a ideia de que tais oportunidades se colocam para todas. Para Janine Esteves e Paulo Rogério Menandro, ${ }^{42}$ que propuseram um recorte de classe social em seu estudo, 'o problema' fundamental está na desigualdade socioeconômica, e não na experiência da gravidez na adolescência. É a redução dessa desigualdade que poderia melhorar as condições de vida das jovens, e não a 'prevenção' da gravidez.

Percebe-se uma diferença significativa dos segmentos populares para os segmentos médios, desconstruindo a ideia de descontinuidade da vida escolar feminina em função da gravidez. ${ }^{43}$ Nas classes populares, a escolaridade já se mostra descontínua anteriormente, no entanto, conforme propõe Ana Lídia Pantoja, ${ }^{44}$ o esforço em retomar os estudos ou dar continuidade a eles demonstra que a própria maternidade na adolescência já fazia parte dos projetos de vida das jovens.

Uma de nossas entrevistadas, Raquel, que poderíamos incluir como pertencendo às camadas populares, 
${ }^{45}$ HEILBORN et al., 2002.

${ }^{46}$ BRANDÃO e HEILBORN, 2006, p. 1428.
47 Lisiane tem 28 anos, é negra, solteira, tem 3 filhos. Atualmente, está fazendo o ensino médio e trabalha na área de assistência social. A renda familiar não chega a dois salários mínimos. relata a maternidade aos 17 anos como um momento de muitas mudanças, tanto corporais quanto sociais. Ela se inseriu cedo no mercado de trabalho por um programa do governo do estado para jovens estudantes. Interrompeu o trabalho logo que se tornou mãe, mas não parou de estudar:

Foi totalmente o oposto da vida que eu tinha. Porque eu trabalhava, estudava, ia para academia, ficava tranquila. E isso já era uma coisa que eu não podia fazer. Não podia me dedicar aos meus cursos, não podia estudar da forma que eu gostaria. Eu tinha que cuidar dele, já não podia. (Raquel)

Já nas camadas médias, geralmente o estatuto social dos jovens e a sua posição na família de origem não se modificam no caso da gravidez. Apesar da ideia de que alguns projetos serão postergados, não se colocam em xeque as expectativas sociais dessa ou desse jovem. ${ }^{45}$ Além disso, o exercício dessa maternidade fica marcado por discursos morais e religiosos, os quais produzem a "ilegitimidade social da parentalidade em tais circunstâncias - fomentada pelos estereótipos sociais sobre a 'irresponsabilidade' adolescente". ${ }^{46}$

Na primeira gravidez de outra de nossas entrevistadas, Lisiane, aos 19 anos, a relação com o namorado da época era tão informal que, quando a filha nasceu, ele não sabia nem mesmo o nome da namorada para vê-la no hospital, conhecia apenas pelo apelido. Nessa época, Lisiane participava de um movimento da igreja católica, participação bastante enfatizada no relato da sua trajetória de vida:

Veio a irmã e disse para mim me retirar: "eu vim aqui para te convidar para te retirar, porque tu vai ser exemplo para outras meninas" [...] Eu fiquei muito chocada com aquilo, mas saí. Aí me enfiei dentro de casa, engordei, eu pesava quarenta quilos, fiquei com oitenta quilos. (Lisiane) ${ }^{47}$

Para lara, a primeira gravidez aconteceu também quando tinha 19 anos. Dentre as mulheres que participaram desse estudo, lara foi a única (das que se incluem na camada média da sociedade) que engravidou antes dos 20 anos, quando namorava o seu atual esposo, com quem se casou em função da gravidez. Logo em seguida perdeu o bebê. Pelo fato de ter uma vida sexual ativa, a educação religiosa que recebeu dos pais foi narrada como uma situação conflitante. Relata que os pais sempre foram vinculados a grupos de casais da igreja católica, inclusive dando palestras sobre a vida sexual do casal. "E durante muito tempo eu ouvi que as mulheres tinham que casar virgem" (lara). Nesse contexto, também a decisão de estabelecer 
${ }^{48}$ Cecília COIMBRA, Fernanda BOCCO E Maria Livia NASCIMENTO, 2005, p. 3.

49 COIMBRA, BOCCO $\mathrm{e}$ NASCIMENTO, 2005.

${ }^{50}$ Luís Antônio GROPPO, 2000.

${ }^{51}$ GROPPO, 2000. uma união formal foi uma tentativa de legitimar a maternidade.

De forma geral, entendemos que as reflexões de algumas participantes acerca da gravidez na adolescência têm uma grande preocupação em mostrar que ser mãe antes dos 20 anos necessita de uma explicação. Essa 'explicação' talvez fosse impensável num contexto histórico anterior, há umas duas ou três gerações, quando, ao contrário, não ter filhos ou não ser casada até os 30 anos representava, então, um problema.

Além disso, colocamos em questão o termo "gravidez na adolescência", como sinalizado em nota anterior, por dois motivos. Primeiro, porque buscamos aqui compreender os enunciados a respeito da maternidade, que não se restringe ao período gestacional. Segundo, porque o termo "adolescência" também pode ser questionado como um produto histórico que "vem servindo aos propósitos dominantes de homogeneização e padronização das práticas sociais e dos modos de existência". ${ }^{48} \mathrm{O}$ conceito de adolescência passa a determinar um modo considerado mais adequado de ser que seria intrínseco a essa fase do desenvolvimento humano, constituindo uma 'identidade adolescente', limitando outras formas de existência.

Algumas autoras ${ }^{49}$ propõem mudar a denominação desse momento da vida para jovem ou juventude, para não estipular faixa etária específica ou comportamentos associados a uma fase, mas como forma de enfatizar a intensidade juvenil e pensar as forças que atravessam esses sujeitos. Já Luís Antônio Groppo ${ }^{50}$ toma a própria concepção de juventude como um produto da cultura ocidental, capitalista, liberal, marcada por caracteres definidores e legitimadores, baseados numa noção evolucionista de ser humano, e que, conforme a disciplina científica que procura dar conta dela, recebe uma denominação distinta, como adolescência ou puberdade, por exemplo. ${ }^{51}$

É interessante pensar essa distinção, em especial neste estudo, para analisar como essas jovens passam a se assumir como mães, tomadas distintamente pelos discursos que legitimam e atribuem valor aos modos de ser mãe. Não tomamos as suas maternidades como diferentes porque estariam situadas numa fase específica do desenvolvimento, mas marcadas intensamente por alguns enunciados que buscam diferenciá-las.

Além disso, pensar o tempo da maternidade remete a algumas reflexões do período inicial do contato com as participantes sobre a idade dos filhos e as mudanças nos modos de ser mãe. No contato inicial com Mara, apesar de incluir-se nos requisitos da pesquisa (ser mãe e ser trabaIhadora), ela adverte que talvez sua trajetória não fosse tão 
interessante para a pesquisa, porque seus filhos já estavam adultos e imaginava que deveríamos falar com mães jovens de filhos pequenos.

$\mathrm{Na}$ entrevista com Mara, essa questão aparece novamente. Para ela, inicialmente a idade dos filhos e a autonomia e independência que conquistaram vêm associadas a uma facilidade no exercício da maternidade. É nesse momento que Mara pôde retomar seus estudos, dedicando-se a outras atividades e interesses:

Hoje eu estou vivendo o melhor momento da minha vida, desde a separação. Por quê? Qual a grande preocupação de uma mãe? É sempre o filho, é se está bem na escola, na creche, hoje os filhos estão independentes, cada um cuidando da sua vida, eu não tenho mais com o que me preocupar, entendeu? (Mara)

Lisete também fala sobre a facilidade que percebe hoje no seu modo de ser mãe, associada à independência dos filhos em relação ao seu cuidado, tendo em vista a idade deles, mesmo pensando no seu neto de 16 anos, que ela assume como filho: "Ele é mais velho, não tem mais nenhuma criança. Se eu não fiz janta eles se viram. Hoje tá mais fácil" (Lisete).

Essa associação do crescimento do filho com uma maior facilidade no exercício da maternidade aponta para a forte relação entre o ser mãe e o cuidado infantil. Nessa colagem dos enunciados da maternidade com o cuidado infantil, o crescimento dos filhos, que geralmente diminui a relação de dependência com a mãe, parece diminuir também as possibilidades de essa mulher reconhecer-se como mãe. Nessa linha, pelo fato de não ter filhos pequenos, dependentes do seu cuidado, Mara sente-se menos autorizada a falar como mãe. Essa restrição também é colocada como produtora de sofrimento: "Por um lado é ruim, eu não tenho mais compromisso, eu estou livre, o que não é bom, eu não sei, eu tenho saudade quando eles eram pequenos que tinha que dar banho, fazer comidinha, servir, dá uma sensação da inutilidade" (Mara).

Nesse sentido, o sofrimento no caso de Mara é produzido pela ideia de que ser mãe é cuidar, associada à ideia de que ser mulher ou ser útil é ser mãe. Então, ao deslocar-se da função de cuidadora, sente-se inútil. Esses enunciados que definem o que é ser mulher e ser mãe de forma tão restrita exigem de algumas mulheres que repensem suas vidas depois que seus filhos se tornaram mais independentes.

É interessante pensar que o crescimento dos filhos e a independência do cuidado materno podem colocar em questão alguns preceitos da normalização que definem o que é ser mãe na contemporaneidade, principalmente a 
ideia de que mãe precisa ter dedicação exclusiva à/ao filha/o. Ao mesmo tempo, essas mudanças de vida das mulheres mais velhas podem ser entendidas também como um efeito desses enunciados, nos quais passam a não mais se reconhecer, buscando outras possibilidades de reconhecimento: na participação política, na vida profissional e na formação acadêmica.

\section{Quem disse que pra ter um filho tem que ter casa própria e carro?}

Torna-se importante refletir sobre as condições (principalmente financeiras) que hoje são entendidas como necessárias na decisão de ter um filho. Nessa normalização, não se pode ser mãe em qualquer condição. Claro que a vinda de um filho não necessariamente respeita essa norma. Mas o exercício da maternidade em condições que não são consideradas adequadas passa a ser entendido como inconsequente.

Esse 'teste' que analisa quem está ou não apto a ter um filho é relatado por algumas mulheres na ocasião em que quiseram ser mães, implicando a definição também de um momento ideal para a maternidade, ou ainda, a decisão de ter ou não mais filhos. Além disso, já sendo mães, essas condições, quando não estão presentes, passam a ser buscadas como projetos de vida dessa mulher, por conta da maternidade.

Após a maternidade, Débora passa a se preocupar mais com a estabilidade financeira da família. Na sua trajetória de vida, isso demanda mudanças importantes no seu modo de viver e seu modo de trabalhar (até então sempre "por conta"):

A gente não pensava muito no futuro, hoje já é uma preocupação constante, como que vai ser, que daqui um pouco tem escola, tem isso, tem aquilo. Nosso planejamento virou a longo prazo [...] Tanto que hoje eu voltei a pensar em estudar, em fazer um concurso pra ter essas garantias. (Débora)

Em relação à estabilidade financeira para ter um filho, no relato de Michele é isso que sustenta a sua decisão de ser mãe:

A gente sempre fez todos os nossos planos sempre contando com essa instabilidade dele, então mais baseada em mim, essa decisão era mais minha nesse sentido de dinheiro. Eu não sei se independente, se egoísta, se teimosa, eu não sei qual o adjetivo, mas geralmente eu faço o que eu quero sabe? Então se o Maurício dissesse "eu não quero ter um bebê agora", lógico que eu ia escutar, mas eu ia questio- 
nar, ia incomodar, ia encher o saco. Então, quer saber de uma coisa eu quero ter um bebê, o bebê é meu, a vontade é minha [...] tô exagerando, por isso eu não sei se isso é independência, teimosia ou egoísmo, mas em algumas coisas eu assumo. (Michele)

A independência marca seu modo de ser mulher e está associada ao discurso neoliberal, acentuado pelo individualismo. Essa posição torna-se possível também pela sua inserção profissional, em função gerencial, alvo de investimentos intensos de princípios desse discurso nas empresas. Nesse discurso, as condições de vida são responsabilidades exclusivas de cada indivíduo e passíveis de serem conquistadas com o devido esforço, invisibilizando os diferentes contextos sociais.

No extremo, esse discurso produz uma necessidade de o sujeito provar sua independência. A autonomia só se torna possível associada ao individualismo, criando a sensação de que o ideal é não se precisar da ajuda de ninguém. Nessa lógica, só pode ter filho, ou ter mais um filho, quem tiver alcançado esse ideal de autonomia: "É que eu acho que na época eu senti uma situação muito de dependência da minha mãe, não sei se a palavra é dependência [...] Então naquele momento eu acho que eu não podia ter outro filho. Como é que eu ir botar mais um filho no mundo se ela já me ajudava" (lara).

Michele fala do momento em que decidiu ter um filho, ressaltando as conquistas materiais do casal, ao mesmo tempo que se questiona se é isso que lhe permite ser mãe:

Ter um bebê, aquela história, a gente tinha casa própria, a gente tinha comprado um carro. Mas quem me disse que pra ter um bebê a gente precisa ter casa própria, ter um carro? Minha mãe dizia isso, precisa ter uma estabilidade pra ter um bebê e eu fiquei pensando por que eu não teria condições de ter um bebê e parei de tomar comprimido. (Michele)

Não posso desvincular a discussão dessas condições ideais para a chegada de um filho do contexto social em que se inserem as mulheres.

Não tenho casa, não sou casada, não tenho carro. Só tenho um celular que mal toca. Como é que eu vou ter filho? Vou ter que começar tudo do zero de novo. Eu não tenho estrutura financeira para assumir [...] usar os cremes que tem que usar. Ter um plano de saúde decente, para a criança quando nascer, ter um acompanhamento. Até eu alcançar todos esses objetivos. Parece que é fácil, mas demanda tempo. (Raquel) 
Se essas condições são tomadas como ideais para todas as mulheres, inegavelmente, há uma diferença muito grande de acesso a elas, conforme o contexto social de cada uma. Associando essas exigências a um discurso individualista, essas condições passam a ser entendidas como responsabilidade única de cada mãe em particular.

\title{
Considerações finais: pensando outras formas de ser mãe
}

\begin{abstract}
"Na verdade, eu não sei se me incomoda ser diferente ou se me incomoda as pessoas quererem que eu seja igual. Então, venho mais para tumultuar a tua pesquisa porque eu estou numa fase de também estar me descobrindo em relação a isso. Porque eu estou sendo provocada a pensar essas coisas." Lisiane
\end{abstract}

Há diferenças importantes que vão sendo marcadas em diversas falas das participantes. Tomando em análise essas falas e o próprio ditado "Mãe é tudo igual, só muda de endereço", pensamos que também esse 'endereço' possibilita diferenças na forma como essas mulheres assumem a maternidade e na abertura com que falam sobre essa diferença em relação à norma. $O$ endereço é entendido como o contexto social em que se inserem e as suas posições sociais em vários momentos (trabalho, escolaridade, geração e inserção em movimentos sociais).

Débora, uma profissional com ensino superior, casada, com 31 anos, encaixa-se numa ideia de família nuclear, considerada como estruturada. Orgulha-se das mudanças que a maternidade Ihe proporcionou. No entanto, num momento muito espontâneo do seu relato, faz o seguinte comentário:

Claro que chega uma hora que ser mãe, na verdade tu quer ser tu, tu não quer ser mãe, tu quer tomar um banho, passar um hidratante, lavar o cabelo, que são situações que tu quer ficar sozinha, que tu quer fazer qualquer coisa e daí [...] Mas nada a ver com a tua pergunta, eu me perdi [dá uma risada aberta, mas envergonhada, parece que deixou escapar algo]. (Débora)

Essa diferença, ou essa tentativa de não assumir a maternidade tal qual esse ideal do que é ser uma boa mãe, surge de forma bem mais aberta, mas não menos sofrida, no relato de Lisiane. Ela diz, durante a entrevista, que não nasceu para ser mãe e relata algumas situações cotidianas no cuidado com os filhos em que não tem paciência, consciente de que a forma como exerce esse papel não corresponde 
ao que se consideraria uma boa mãe: "não nasci para ser mãe, criança chora, me estressa, me irrita" (Lisiane).

Primeiramente isso parece estar associado ao fato de que essa não foi uma função que ela tenha desejado para sua vida:

Outro detalhe muito importante, eles não me chamam de mãe [...] Porque eu náo tenho essa coisa, eu não me imaginei ser mãe. Chegou uma época da minha vida que eu fui. Eu tinha meus planos, morar sozinha, construir minha vida, fazer uma faculdade, ser doutora. Em nenhum momento eu pensei em ser mãe. E aí quando eu me vi mãe. É que nem a piada que a minha vó [...] Se o estupro é inevitável relaxa e goza, só que capricha. E é isso que eu tenho feito até hoje, tenho estado com eles, tenho levado, tenho feito meu papel. Mas não é uma coisa que foi sonhada, planejada. (Lisiane)

Apesar de assumir e responsabilizar-se pelos seus filhos, exerce de forma diferente esse papel, deixando explícito que não encontra, nessas atividades, grandes prazeres. Parece que, por marcar essa diferença, não consegue se reconhecer e ser reconhecida como mãe, mesmo que se encaixe em outras categorias maternas, imersas em relações de poder, como, por exemplo, "mãe ausente":

Eu entendo que ser mãe é ser mais do que eu sou. Não sou uma mãe boa. Eu sou uma mãe ausente. A prioridade para minha vida agora tem sido meu trabalho, até porque é com ele que eu sustento eles. Mas se eles estão doentes paro trabalho, para tudo, mas se não tiver eu acho que não tem essa coisa do estar junto [...] Eu odeio estar dentro da minha casa, porque começa aqueles berros, assim não é prazeroso. Então mãe, eu acredito que mãe é uma pessoa que, no meu contexto, gosta de ser mãe, de estar resolvendo este tipo de conflito, de estar apaziguando. Eu não. (Lisiane)

Esse posicionamento tão marcado na diferença parece ser possível para Lisiane por meio da sua inserção em movimentos sociais de contestação. Apesar de reivindicar a diferença, ela ainda usa a norma como parâmetro de maternidade, quando se apresenta como uma mãe ausente: "Eu quero que minha filha tenha um outro olhar [...] Então são essas escolhas que eu acho que eu sou mais mãe nesse sentido, mas eu não sou só a mãe carinhosa. Eu acho que eu sou uma mãe prática, sabe, de criar as possibilidades" (Lisiane).

Nesse sentido, pensamos esses enunciados a respeito da maternidade como formas de produzir um modo de ser mãe que passa a ser considerado mais adequado. Eles 
mesmos só são possíveis tendo como referência outras maternidades que passam a ser desprestigiadas, mas permanecem como alternativas de existência.

Descrevemos neste trabalho enunciados que passam a configurar a norma reguladora de práticas maternas. Em especial, enunciados que definem o número de filhos por mulher, que pode estar associado tanto com as preocupações demográficas quanto com as preocupações sobre as necessidades econômicas e afetivas de cada criança; enunciados que definem o tempo da maternidade, para que as mães sejam maduras ou estáveis suficientes para dar conta dessa tarefa, mas não muito velhas biologicamente; e enunciados que definem as condições econômicas para esse momento, os quais colocam a reprodução como um projeto individual, de responsabilidade de cada mulher ou família.

Apesar de esses enunciados serem tomados como a norma de maternidade e estarem presentes nos diferentes relatos, a diversidade de marcas sociais e contextos que posicionam essas mulheres como sujeitos permite diferentes modos de se relacionar com essa norma. Colocamos em suspensão o ditado que nomeia este artigo, "Mãe é tudo igual", para ressaltar as rupturas na ideia de igualdade no exercício da maternidade e, ao mostrar a diversidade, apontar também para modos de existir que potencializam outras formas de ser mãe.

\section{Referências bibliográficas}

AQUINO, Estela Maria Motta Lima Leão de. "Adolescência e reprodução no Brasil: a heterogeneidade dos perfis sociais". Cad. Saúde Pública, Rio de Janeiro, v. 19, p. 377-388, 2003. Suplemento 2.

AZEVEDO, Kátia Rosa; ARRAIS, Alessandra da Rocha. "O mito da mãe exclusiva e seu impacto na depressão pósparto". Psicologia: Reflexão e Crítica, v. 19, n. 2, p. 269276, 2006.

BADINTER, Elizabeth. Um amor conquistado: o mito do amor materno. São Paulo: Círculo do Livro, 1998.

BRANDÃO, Eliane Reis; HEILBORN, Maria Luiza "Sexualidade e gravidez na adolescência entre jovens de camadas médias do Rio de Janeiro, Brasil". Cad. Saúde Pública, Rio de Janeiro, v. 22, n. 7, p. 1421-1430, jul. 2006.

CASTEL, Robert. As metamorfoses da questão social: uma crônica do salário. Petrópolis: Vozes, 1998.

COIMBRA, Cecília; BOCCO, Fernanda; NASCIMENTO, Maria Livia. "Subvertendo o conceito de adolescência". Arquivos Brasileiros de Psicologia, Rio de Janeiro, v. 57, n. 1, p. 2-11, 2005. 
ESTEVES, Janine Raymundi; MENANDRO, Paulo Rogério Meira. "Trajetórias de vida: repercussões da maternidade adolescente na biografia de mulheres que viveram tal experiência". Estudos de Psicologia, Natal, v. 10, n. 3, p. 363370, 2005.

FIDALGO, Lurdes. (Re)construir a maternidade numa perspectiva discursiva. Lisboa: Instituto Piaget, 2003.

FORNA, Aminatta. Mãe de todos os mitos. Como a sociedade modela e reprime as mães. Rio de Janeiro: Ediouro, 1999.

FOUCAULT, Michel. A história da sexualidade l: a vontade de saber. Rio de Janeiro: Edições Graal, 1988.

"Nietzsche, a genealogia e a história". In: MACHADO, Roberto (Org. e Trad.). Microfísica do poder. 11. reimpressão. Rio de Janeiro: Edições Graal, 1995. p. 15-38. - A arqueologia do saber. 7. ed. Rio de Janeiro: Forense universitária, 2005.

GROPPO, Luís Antônio. Juventude: ensaios sobre sociologia e história das juventudes modernas. Rio de Janeiro: DIFEL, 2000.

HEILBORN, Maria Luiza et al. "Aproximações socioantropológicas sobre a gravidez na adolescência". Horizontes Antropológicos, Porto Alegre, ano 8, n. 17, p. 13-45, jun. 2002.

MEYER, Dagmar Elisabeth Estermann. "A politização contemporânea da maternidade: construindo um argumento". Revista Gênero, Niterói: NUTEG-EDUFF, v. 6, n. 1, p. 81-104, 2006.

NARDI, Henrique Caetano. Ética, trabalho e subjetividade: trajetórias de vida no contexto das transformações do capitalismo contemporâneo. Porto Alegre: Editora da UFRGS, 2006.

PANTOJA, Ana Lídia Nauar. "'Ser alguém na vida': uma análise sócio-antropológica da gravidez/maternidade na adolescência, em Belém do Pará, Brasil". Cad. Saúde Pública, Rio de Janeiro, v. 19, p. 335-343, 2003. Suplemento 2.

REDE INTERAGENCIAL DE INFORMAÇÕES PARA A SAÚDE. RIPSA. Indicadores e dados básicos para a Saúde - 2007 no Brasil: conceitos e aplicações. Brasília: OPAS, 2008. Disponível em: http://tabnet.datasus.gov.br/cgi/idb2007/ tema.pdf. Acesso em: 30 ago. 2009.

RIO GRANDE DO SUL. Gabinete da Primeira-Dama. Te Liga. Gravidez Tem Hora. Cláudia Rigotto lança Campanha de prevenção à gravidez na adolescência. Projetos, 2006. Disponível em: http://www.primeiradama.rs.gov.br/ . Acesso em: 14 nov. 2006.

Secretaria da Educação destaca reflexos do planejamento familiar na educação. 2 ago. 2007. Disponível em: http://www.estado.rs.gov.br/. Acesso em: 5 jan. 2008. 
SORJ, Bila; FONTES, Adriana; MACHADO, Danielle Carusi. "Políticas e práticas de conciliação entre família e trabalho no Brasil". Cadernos de Pesquisa, São Paulo, v. 37, n. 132, p. 573-594, set./dez. 2007.

TAIN, Laurence. "Um filho quando eu quiser? O caso da França contemporânea". Revista Estudos Feministas, Florianópolis, v. 13, n. 1, , p. 53-67, jan/abr. 2005.

YALOM, Marilyn. A história do seio. Lisboa: Teorema, 1997.

[Recebido em agosto de 2008 e aceito para publicação em abril de 2009]

\section{Are Mothers all Alike? Statements producing Contemporary Motherhoods}

Abstract: This article analyses the statements related to motherhood that configure what we call motherhood "norm". We follow Foucault's theory, mainly in reference to genealogy as a way to think about the present. The analysis was conducted mainly on working mothers' life trajectories description. This research material allowed us to question some statements that constitute contemporary motherhood. We described the intensification of the investment in a woman pattern as the result of motherhood norm. This norm, although socially produced is naturalized nowadays. It works determining some characteristics that configure the good way to be mother, as such: correct time to be a mother (age), number of children, and financial conditions. As an effect of the norm we have an evaluation and hierarchization of different ways of being a mother.

Key Words: Motherhood; Statement; Discourse; Modes of Subjectivation. 